\title{
THE DEVELOPMENT OF GASTRULA ECTODERM IN REGENERATING TISSUE OF RANA PIPIENS LARVAE ${ }^{1}$
}

\author{
HENRY S. EMERSON \\ Department of Anatomy, University of Michigan, Ann Arbor \\ ONE TEXT FigURE AND TWO PLATES (TEN FIGURES) \\ INTRODUCTION
}

In a previous paper (Emerson, '40) the regenerating tail blastema of anuran larvae was shown to be a very favorable environment for the development of embryonic tissues. Presumptive hindbrain from the neurula stage differentiated into a typical medulla in the midst of blastema mesenchyme. The posterior third of the neural plate developed into a spinal cord scarcely distinguishable from a normal cord of the same age. Even a small flat piece of ectoderm from the presumptive otic vesicle region formed a recognizable ear with sensory and nonsensory areas. Blastema mesenchyme, therefore, is a highly satisfactory environment for the morphogenesis as well as the histogenesis of embryonic organs.

These results with neurula stage grafts suggested a study of the differentiation of early gastrula ectoderm in the same environment. This is of theoretical interest because the development of gastrula ectoderm depends to a large extent on the medium surrounding it. In salt solution pieces of both presumptive epidermis and neural plate form disorganized groups of generalized epithelial cells, and with anuran donors suckers may develop also (Holtfreter, '38b). The same gastrula

\footnotetext{
1 The author is indebted to the Department of Biology, Amherst College, Amherst, Massachusetts, for the use of their laboratory during the summer and for much helpful criticism.
} 
regions in the larval coelom develop into either typical epidermis and dermis, or nervous tissue (Holtfreter, '31 a). And in the larval eye cavity urodele gastrula ectoderm differentiates into epithelial cells, notochord, and muscle tissue, while anuran ectoderm forms nervous tissue, cartilage, and endodermal epithelium (Kusche, '29, '30; Bautzmann, '29 b).

The present paper reports an extensive study of the differentiation of gastrula ectoderm in the midst of blastema tissue. The results show that the blastema is about as good an environment for the development of gastrula ectoderm as it was for the neurula grafts mentioned above. The results also demonstrate that blastema tissue differs considerably in its effect on gastrula ectoderm from any of the previously studied media.

\section{MATERIALS AND METHODS}

Both the host larvae and the donor embryos were Rana pipiens which were obtained by the usual pituitary injection technique. The donors were gastrulae in the following four stages, the earliest recognizable gastrula, crescent-shaped dorsal lip, horseshoe-shaped dorsal lip, and oval blastopore. In each case the extent of invagination of the mesoderm as revealed during operation was measured and recorded.

The areas of gastrula ectoderm that were transplanted are shown in the diagram (fig. 1). To obtain the graft a midsagittal strip about the width of the dorsal lip was removed from the embryo and gently flattened out on the silk operating table. The length of the graft was measured with an ocular micrometer, using the dorsal lip as a reference point. The width of the transplant was then cut to equal its length, so that a square of ectoderm was obtained. Two of the areas indicated on the diagram were usually included in the graft, since the larger transplant could be handled with less injury during operation. According to the anlage plan of Vogt ('29 b) for the anuran gastrula areas 5 and 6 are presumptive epidermis, area 4 includes both presumptive epidermis and neural plate, and area 3 is within the presumptive neural plate region. 
Moreover, both areas 3 and 6 are some distance removed from the presumptive mesoderm of the marginal zone.

The host larvae were 3 to $4 \mathrm{~cm}$. Rana pipiens tadpoles. The tails were amputated with iris scissors halfway between the base and the tip. The operations were made when the blastema was from 3.5 to $4.5 \mathrm{~mm}$. long. It required from 7 to 20 days to form a blastema of this size, the length of time depending on the age of the larva, the temperature, and other factors.

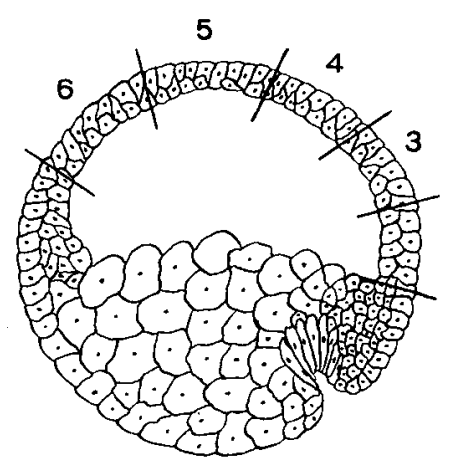

Figure 1

To prepare the blastema for the graft a shallow cut was made with iridectomy scissors along the line of junction between the regenerating and the old tissues. Two cuts were then made a short distance from the dorsal and ventral surfaces of the blastema, at right angles to the original cut. The blastema epidermis outlined by the three cuts, together with a thin layer of mesenchyme, was separated from the rest of the blastema, so that a flap of regenerating tissue was produced. The transplant was then placed while still perfectly flat beneath this tissue flap. The grafts were usually oriented with the outside of the ectoderm facing the blastema flap, but a few operations were made with the opposite orientation. The operations were made in a solution of 1.0 part M. S. 222 to 14,000 parts Holtfreter's solution. In order to insure healing the larvae were left in the anaesthetic for $\frac{1}{2}$ hour after opera- 
tion. With this method no animals failed to come out of the anaesthetic, and complete and permanent healing occurred in every case.

\section{RESULTS}

\section{Differentiation of the transplants}

The first series of cases were fixed from 7 to 11 days after operation. A summary of the operations and results is given in table 1. The transplants classified as disintegrated formed no recognizable tissue and are in various stages of resorption. All that remains of these grafts is a mass of scattered undifferentiated cells, pigment granules and yolk platelets. Disintegration was more frequent with the smaller grafts, which is the reason the larger transplants were used more often.

TABLE 1

\begin{tabular}{|c|c|c|c|c|c|c|c|}
\hline AREA & $\begin{array}{c}\text { NUMBER } \\
\text { OF } \\
\text { CASES }\end{array}$ & $\begin{array}{c}\text { DISIN- } \\
\text { TEGRATED }\end{array}$ & EPIDERMIS & SUCKER & $\begin{array}{l}\text { NERVOUS } \\
\text { TISSUE }\end{array}$ & CARTILAGE & DERM IS \\
\hline 3 & 17 & 8 & 7 & 9 & 1 & & 6 \\
\hline 4 & 17 & 9 & 8 & 7 & & & 7 \\
\hline $3-4$ & 23 & 6 & 12 & 14 & 7 & 2 & 10 \\
\hline $4-5$ & 13 & 4 & 9 & 8 & 2 & & 6 \\
\hline $5-6$ & 28 & 6 & 20 & 14 & 13 & 4 & 14 \\
\hline Total & 98 & 33 & 56 & 52 & 23 & 6 & 43 \\
\hline
\end{tabular}

The most frequent graft derivative is a regular epithelium which is recognizable as an early stage in the formation of epidermis. A low power view of a typical case is shown in figure 2. The epithelium forms an oval vesicle with scattered clumps of pigment granules in the lumen. The wall of the vesicle is a regular, single layered cuboidal epithelium. Some of the cells are ciliated on the surface facing the lumen, but this is not evident in the photograph. Many of the cells have pigment granules concentrated in the end of the cell toward the lumen. The regular cuboidal epithelium, cilia, and distribution of pigment granules all indicate a stage in the differentiation of epidermis, with the outside of the epidermis facing the inside of the vesicle. 
The epidermis forms a similar vesicle in fifty-one cases, while in the other five instances the epithelium is a flat plate of tissue. The lumen of the vesicles is sometimes largely free of solid matter, but there are often pigment granules in the lumen as in the case photographed. In still other instances the lumen is nearly full of disintegrated cells, pigment granules, and yolk platelets. The epithelium is usually a single cell in thickness, but it may be two or several cells thick for short distances. The height of the epithelium varies from low columnar to squamous, but it is cuboidal in the great majority of instances. Mitotic figures are rather frequent, and the yolk platelets may or may not have been all used up at the time of fixation. There may be cilia on the inner surface of the epithelium, and pigment granules are of ten concentrated in the ends of the cells facing the lumen (figs. 2 and 3). The position of the cilia and the distribution of pigment granules show clearly that the outside of the epidermis faces the inside of the vesicle. This is true of all cases in which the polarity of the epithelium is distinguishable, and there are only two instances in which the orientation cannot be determined.

Well differentiated suckers were formed nearly as frequently as epidermis. A typical case is shown in figure 5, in which the characteristic sucker histology is unmistakable. The layer of very tall almost completely hyaline sucker cells is conspicuous. The nuclei are toward the base of the cells, but they are a little more irregular in position than in the normal gland. Also near the base of the cells there are pigment granules and occasional vacuoles. The sensory layer of the epidermis directly surrounds the sucker cells. It is a regular cuboidal epithelium, and definitely darker stained than the sucker cell layer. The surface of the sucker cells toward the lumen is covered with stringy highly pigmented mucus, which shows that the gland was in active secretion when fixed. The sucker is obviously oriented with the outside surface toward the lumen of the vesicle.

In the other cases of sucker formation the gland either composes the entire graft, as in figure 5, or it is limited to a small 
part of an epidermal vesicle. One of the smaller suckers is shown in figure 6 , and the characteristic cup-shaped form is more evident in this case. There are all conditions intermediate in size between these two extremes among the various instances. The histological structure is always as typical as in the grafts pictured, and the majority of the suckers were in active secretion at the time of fixation.

It is shown in table 1 that nervous tissue occurred in twentythree instances, or in about one-third of the well-developed grafts. In eight of these cases there is a considerable amount of typical nervous tissue which is clearly divided into fibrous and cellular portions. One of the grafts is shown in figure 4, and besides the nervous tissue the transplant has also formed an epidermal vesicle. Seven of the other cases are essentially similar, although one of them is entirely composed of nervous tissue. In the remaining fifteen grafts there is merely a small trace of nervous tissue on a few sections. Nervous tissue, therefore, is not as abundant a graft derivative as might be judged from the table.

Of the six grafts recorded as forming cartilage only two have developed the definitive tissue. The other four are still in the stage of procartilage. The tissue is somewhat mesenchymal, but its procartilage nature is unmistakable, since the cells are nearer together, the nuclei more regularly oval, and the intercellular substance denser and less fibrous. The graft origin of the cartilage and procartilage is shown by pigment granules both in the cells and in the matrix. Moreover, there is no blastema cartilage developed at the time these cases were fixed. Possibly cartilage might have appeared more often in this series if the grafts had developed a longer time before fixation.

In figure 3 a typical dermis is visible underlying the epidermis. The dermis is composed of a row of flattened fibroblasts in a thin layer of parallel collagenous fibers. Usually there are a few chromatophores in the dermis, although not in the section photographed. The chromatophores are as a rule elongated and closely flattened against the base of the 
epidermis, and several of them are evident in figure 2 . The dermis is rarely as extensive as in figure 3. In the great majority of cases there is merely a trace of dermis underlying a small part of the epidermal vesicle.

At present it cannot be decided certainly whether the dermis is of host or donor origin. The fibroblast nuclei are somewhat darker, more condensed, smaller and more regularly oval than most of the nuclei of the blastema mesenchyme. However, these qualities of the dermal nuclei are not completely outside the range of variability of the blastema mesenchyme nuclei, so they are not conclusive criteria. In some cases there are yolk platelets in the epidermis, whereas there are never any yolk platelets in the cells of the dermis. But there is hardly room for any yolk platelets in the scanty cytoplasm of the flattened dermal fibroblasts. It is hoped that xenoplastic experiments may eventually demonstrate the origin of this dermis, but such operations have been unsuccessful so far.

A small amount of notochord and muscle tissue was found in two exceptional cases. The muscle forms small irregular myotomes on each side of the notochord. The graft origin is shown by pigment granules in the cells and by the tissue arrangement which is unlike anything present in the blastema of this age. In these two instances the grafts were areas $3+4$, and probably in both cases area 3 included some marginal zone material. This could be due to either error in measurement during operation, or to variability in the extent of the marginal zone in individual gastrulae.

As shown in table 1, presumptive epidermis and presumptive neural plate develop in essentially the same way in the blastema. Both definitive epidermis and nervous tissue come from either of the two presumptive regions, and with about equal frequency. Suckers are not limited to the presumptive sucker area, but occur just as often from any other ectodermal region. And cartilage also is not localized in any particular part of the ectoderm. These results will be considered further in the discussion. The age of the gastrula ectoderm also made no difference in the results. The graft derivatives were 
the same for all gastrula stages used, and as mentioned above these varied from the earliest appearance of the dorsal lip to the oval blastopore stage. With the older donors care was taken to avoid any ectoderm already underlain by mesoderm.

\section{Further development of the transplants}

Eight grafts were allowed to develop for 19 or 20 days before fixation, in order to study their further differentiation. The transplants were either area $5+6$ or $3+4$. In two of these cases all that remains of the grafts is a few scattered clumps of pigment granules. The other six grafts continued to develop and reached a stage of differentiation beyond that of any of the earlier fixed cases.

Figure 7 is a section through one of the best developed grafts. The transplant has formed an epidermal vesicle about twice as large as any developed from the younger grafts. The lumen is largely empty except for a few scattered pigment granules. The wall of the vesicle is composed of definitive larval epidermis, with the superficial and sensory layers clearly differentiated. The superficial layer is made up of the typical flattened, highly pigmented cells which in some places are bound together by intercellular bridges. The underlying sensory layer of very regular cuboidal epithelium is equally characteristic. There are mitoses in some of the cells of the sensory layer, and all yolk platelets are completely used up. A few epidermal melanophores are scattered among the other cells of the epidermis, and one of these is visible in figure 7 . In a few places the epidermis is underlain for a short distance by a dermis composed of a thin layer of collagenous fibers, a single row of flattened fibroblasts, and a few melanophores. As in the earlier fixed cases the origin of the dermis cannot be decided with certainty.

Two of the other well-developed grafts are essentially similar to the one just described. The differentiation of superficial and sensory layers is just as evident, although not quite so extensive. It is clear that gastrula ectoderm can form definitive epidermis with typical superficial and sensory layers, 
if left in the blastema a sufficiently long time. However, all the grafts in this series did not develop so far, since in three cases the epidermis is similar to the earlier fixed grafts described in the preceding section. In two of these the usual oval epidermal vesicle was not formed. Instead the graft is composed of branching and anastomosing strands of regular cuboidal epithelium, one or two layers thick. Part of the epithelium is ciliated, and there are occasional epidermal melanophores between the other cells. The anastomosing strands of epithelium form a network with the interstices filled up by blastema mesenchyme. Such a condition was never found in the earlier fixed grafts. It suggests that in these two instances the usual hollow vesicle may have been formed at first, and then secondarily invaded and broken up by host mesenchyme.

Cartilage was not found in any of these cases, and only one formed a small amount of nervous tissue. None of the grafts developed suckers, although in two of them there is a mass of stringy pigmented mucus in the lumen of the vesicle that looks like sucker secretion. Suckers may have been present earlier in the transplants, since if the development of the suckers was normal they would have disappeared before these grafts were fixed.

\section{Early development of the grafts}

A piece of embryonic ectoderm in salt solution rounds up into a tight ball with the outside of the ectoderm invariably facing the outside of the ball. The epidermal vesicles in the blastema, however, have just the opposite orientation of the epidermis. A study of the early development of the grafts has shown how this result is brought about. Forty-three operations were made in this series, and the transplants were either area $3+4$ or $5+6$. The cases were fixed from 1 to 6 days after operation. The sections show that thirteen of the grafts largely disintegrated, while the remaining thirty continued to differentiate. 
Direct observation on the living grafts gave some information about the early development. The outer pigmented surface of the ectoderm and the inner clear side are distinctly visible through the blastema just after operation. After about a day the difference in pigmentation between the two surfaces becomes less, and the blastema tissue over the graft is thicker, so that the two sides of the ectoderm are no longer distinguishable with certainty. All the grafts in this series were studied carefully while living until the time of fixation. In the majority the grafts partly curled up during the first day with the outside of the ectoderm outside, in the manner normal for explants in salt solution. Only six of the grafts remained largely flat until the end of the first day and there were no cases which even began to curl in the opposite way.

The histological study of two cases fixed after 1 day checked completely with the observations on the living grafts. A section of one of these transplants is shown in figure 8. It was recorded just before fixation as partly curled up. The photograph shows that the highly pigmented outer side of the early ectoderm covers the whole outside of the graft except for a short distance. The other transplant was recorded before fixation as nearly completely curled, and in the sections the pigmented outer side covers even more of the surface of the graft than in the case illustrated.

Six cases were fixed 2 days after operation. Three of these grafts are still largely curled just like the day-old cases, but the edges of the transplant are curved slightly in the opposite direction. The condition is plainly evident in figure 9. In one of the other 2-day-old grafts the curling of the edges of the transplant has gone further, as shown in figure 10. In this case the edges of the graft have curved around until they nearly complete the formation of a vesicle with the original outer surface of the ectoderm on the inside. In the final 2-dayold graft the curving of the edges of the transplant has formed a complete vesicle with the original outside of the ectoderm facing the inside. The condition is similar to that shown in figure 11, although the photograph is of a graft fixed a day 
later. The difference in degree of pigmentation of the outside and inside of the ectoderm is not so great as in the previous instances, although still clear enough to distinguish the polarity of the epithelium. Instead of a single lumen there are several small lumina situated in a row toward the original outer surface of the graft, and the cells around the lumina are in an early stage of sucker formation. The rest of the outer layer of graft cells forms a cuboidal epithelium somewhat differentiated from the inner core of polyhedral cells.

The 3- and 4-day-old grafts may be considered conveniently together. All of these cases have progressed beyond the earliest stage of differentiation illustrated in figure 8, with the outside of the graft mostly covered by the pigmented outer side of the ectoderm. There are, however, two grafts in the next stage of development, with the edges of the transplant slightly curled up. These two cases are essentially similar to figure 9, except that early sucker cells cover part of the surface of both of the grafts. Although the sucker cells are in an early stage of differentiation, yet the deeply pigmented base and perfectly hyaline outer border makes their recognition certain.

The six remaining 3- and 4-day-old grafts have formed closed vesicles with the original inner surface of the ectoderm on the outside, and one of them is shown in figure 11. In the case photographed there are several small lumina situated toward the original outer side of the ectoderm. Two of the other grafts are similar in this respect, while the remaining three have a single small round lumen instead of several lumina. In all cases the lumina are surrounded by early sucker cells, and all the grafts have an outer layer of cuboidal epithelium somewhat differentiated from the inner mass of polyhedral cells.

All of the 5- and 6-day-old grafts developed at least as far as the 3-day-old transplants which formed closed vesicles with the original inner surface of the ectoderm outside. The majority of these cases are quite similar to the 3-day-old graft photographed in figure 11 which has been described 
above. The other 5- and 6-day-old grafts are the same except that there is a single larger lumen which occupies from a third to a half the volume of the transplant, and the sucker cells surrounding the lumen are further advanced than in the previous cases. Two of these latter grafts were fixed after 6 days, and they have developed into vesicles much the same as the 7- to 11-day-old cases described in the first section. The lumen in these vesicles is partly surrounded by tall secreting sucker cells, and partly by a cuboidal epithelium one to several cells thick. The cells are still full of yolk platelets, and the lumen is in part filled with yolk platelets, pigment granules, and a few undifferentiated cells.

This series considered together shows the essential features of the manner of formation of the definitive epidermal vesicles, and it demonstrates clearly how the outside of the epidermis gets to be facing the lumen. A summary of these findings and a consideration of their possible significance will be given in the discussion.

\section{Transplants of ectodermal balls}

In this series the graft was kept in Holtfreter's solution before transplantation until it had completely rolled up into a ball with the outer ectodermal surface outside. The period in salt solution required for this to occur was from 1 to 5 hours. The reason for the series was to compare the development of such transplants with the differentiation of the flat ectodermal grafts previously used. The particular purpose was to find out whether these ectodermal balls would develop into epidermal vesicles with the outside of the epidermis inside, similar to those described above. The transplants were either area $3+4$ or $5+6$. Eleven operations were fixed after 7 or 8 days, and nine were fixed from 2 to 5 days after operation. The sections show that four of the grafts disintegrated, while the other sixteen are well differentiated. The results can be described briefly, since the ectodermal balls developed much the same as the flat ectodermal grafts, except for a slower rate of development in many cases. 
The 7- and 8-day-old transplants will be described first. Four of these developed into epidermal vesicles much like those found in the previous series of operations. The walls of the vesicles are partly one or two layered regular cuboidal epithelium, and partly tall definitive sucker cells. The presence of stringy pigmented mucus shows that the sucker cells are in active secretion. All the suckers point inward toward the lumen of the vesicle, so that the polarity of the epidermis is just opposite to that of the original ectodermal ball. In one instance part of the graft forms a mass of nervous tissue, with a separation into fibrous and cellular areas. In another case there is a small amount of muscle and notochordal tissue of donor origin. As in the two exceptional flat ectodermal grafts that formed mesodermal tissues, the transplant was area $3+4$.

The other six 7-and 8-day-old grafts formed in each case an oval mass of cells with several small lumina surrounded by sucker cells in an early stage of differentiation. The small lumina are arranged in a row toward the original outer ectodermal surface. The outermost cells form a layer of regular cuboidal epithelium differentiated from the inner mass of polygonal cells. The cells are full of yolk platelets, and there are frequent mitoses. These cases are all essentially similar to the 3-day-old flat ectodermal graft illustrated in figure 11. The majority of the ectodermal balls, therefore, have not developed as far as the flat transplants in the same length of time.

The 2- to 5-day-old transplants tell a consistent story of development. None of them remained as complete ectodermal balls with the outer surface outside. Four of the grafts, however, are still largely rolled up in this way, but the edges are curled up slightly in the opposite direction. These cases are virtually identical with the 2-day-old flat ectodermal graft pictured in figure 9 . They were fixed either 2,3 or 4 days after operation. One of the other 4-day-old grafts has the edges further curled opposite to the original curvature, so that it is similar to the case illustrated in figure 10 . In the 
remaining transplant the secondary curling of the edges of the graft has formed a complete vesicle with the original outer ectodermal surface inside. This case was fixed after 3 days, and it is essentially similar to the flat transplant of the same age shown in figure 11.

These younger cases considered together show that the ectodermal balls in the blastema flattened out and eventually curl up in the opposite direction, which is just like the early action of the flat ectodermal grafts. Both types of transplants, therefore, have comparable early development as well as similar final differentiation. This result will be considered further in the discussion.

\section{DISCUSSION}

A brief review of the reaction of embryonic ectoderm in other environments will be helpful for comparison with the results just described. In salt solution the differentiation of gastrula ectoderm is quite meager (Holtfreter, '38 a and b). Urodele ectoderm develops into a disorganized mass of generalized epithelial cells, but no definite tissue. Anuran ectoderm is similar except that suckers are formed also. The suckers come from any region of the ectoderm with about equal frequency; they are not limited to the presumptive sucker region. Differentiation of gastrula ectoderm progresses considerably further in the larval coelom or lymph sac (Holtfreter, '31 a). In this environment the gastrula ectoderm forms definitive epidermis accompanied with dermis, and nervous tissue. The results are the same with both presumptive epidermis and neural plate and with urodele and anuran ectoderm. Occasionally sensory structures develop, in one case a nasal sac, and in several instances ear vesicles usually with a ganglion.

In the larval eye cavity urodele gastrula ectoderm forms either epidermoid epithelium or notochord and muscle tissue, in about equal amounts (Kusche, '29). This surprising result was thoroughly confirmed by Bautzmann ('29). Anuran gastrula ectoderm apparently develops quite differently in 
the same location (Kusche, '30). With anuran donors early gastrula ectoderm forms epidermoid epithelium, nervous tissue, and cartilage, while older gastrula ectoderm forms cartilage and occasionally endodermal epithelium with goblet cells. Unfortunately this work with anuran material has only been described in a brief note.

Anuran ectoderm in the blastema clearly differs from either anuran or urodele ectoderm in the larval eye cavity. The most striking difference is that neither endodermal nor mesodermal tissues are normal derivatives of gastrula ectoderm in the blastema. Endodermal epithelium was never found in the present study, and the three exceptional cases of notochord and muscle in a total of 169 operations are reasonably explained as due either to error in measurement, or variations in the extent of the marginal zone in different donors. In other ways gastrula ectoderm develops further in the blastema than it does in the larval eye cavity. In the eye cavity the ectoderm forms epidermoid epithelium, while in the blastema definitive epidermis develops which is differentiated into typical superficial and sensory layers. Finally, the well-formed suckers so numerous in the blastema are apparently never developed in the larval eye cavity (Kusche, '30).

The reaction of gastrula ectoderm in salt solution is similar to its development in the blastema in one important respect, since suckers occur in both environments. They come from all ectodermal regions, and they appear with about the same frequency in both environments. In most other ways, however, the two locations are different in their effect on gastrula ectoderm. Definitive epidermis, nervous tissue, and cartilage are typical ectodermal derivatives in the blastema, but none of these ever occur in salt solution (Holtfreter, '38 a). Blastema mesenchyme, therefore, is a much more favorable environment than salt solution for the differentiation of gastrula ectoderm.

The blastema is more nearly similar to the larval coelom in its effect than to the other two environments just discussed. In both locations definitive epidermis and nervous tissue de- 
velop. However, there is one striking difference between the epidermis in the two cases. In the larval coelom the epidermis forms a vesicle with the outer layer of the epidermis facing the outside, and with the interior of the vesicle filled with loose mesenchyme (Holtfreter, '29 b). An epidermal vesicle is also formed in the blastema, but the epidermis has the opposite orientation with the outer layer facing the inside of the vesicle, and there is never any mesenchyme in the lumen. This difference cannot be due to the method of operation. In the coelom experiments the graft was allowed to roll up into a ball before implantation. In one series of the blastema operations the graft was treated in the same way, yet the definitive epidermis still faced the inside of the vesicle. There are other less important differences between the two environments. In the coelom nervous tissue and dermis occur much more frequently than they do in the blastema, but these differences are less striking than the opposite polarity of the walls of the epidermal vesicles in the two locations.

In the blastema as well as in the other media discussed above the derivatives of gastrula ectoderm are not confined to their presumptive regions. This is shown clearly in table 1. The presumptive area for mesectodermal cartilage in the gastrula is a narrow strip between presumptive epidermis and neural plate (Harrison, '38). But in the present study cartilage formation was not confined to this region; in fact, more cases of cartilage development occurred from outside this area. The presumptive sucker location is limited to a small portion of area 4 (Vogt, '29 b), but in the blastema suckers come from any part of the ectoderm with about the same frequency. This result is similar to the finding of Holtfreter ('38 b) with anuran ectoderm in salt solution. Finally, epidermis develops in the blastema about as often from presumptive neural plate as it does from presumptive epidermis, and the same is true of nervous tissue. All of these tissues and organs, therefore, come from any portion of the ectoderm with approximately the same frequency. 
These results cannot be explained on the basis of overlapping embryonic fields, since there is no detectable difference in the reaction of the different parts of the ectoderm. To explain his results with ectoderm in the larval coelom, Holtfreter ('31 a) postulates some substance in the coelomic fluid which specifically furthers nervous differentiation. This explanation might be stretched to cover all the ectodermal derivatives found in the blastema, but it would undergo considerable strain in the process. Holtfreter (' $38 \mathrm{~b}$ ) explains the formation of suckers from any ectodermal region in salt solution as due to the release of a small portion of ectoderm from its embryonic environment. The localization of suckers in normal development is attributed to lack of inhibitory factors in the sucker region which are present elsewhere in the embryo. These inhibitory factors may be simply positive stimuli to the formation of some other organ, although this possibility is not considered. The results in the blastema may also be due in part to the release of a small ectodermal area from its normal environment. Moreover, general conditions favorable to development in the blastema can explain why differentiation is more complete and more diverse in this location than in salt solution. In the blastema experiments the mesenchyme surrounding the embryonic cells is itself a growing, proliferating tissue, so that it is more like the normal embryonic environment of the grafts than any of the media previously studied. The variety of the ectodermal derivatives in the blastema, therefore, may be partially explained by favorability of the new location, combined with the release of the graft from its normal environment. These considerations obviously provide an explanation of the results only in a very limited and unsatisfactory sense.

A more direct explanation of one of the chief results of this investigation is possible; namely, the development of definitive epidermis from gastrula ectoderm. In normal development the formation of epidermis depends upon the morphogenic influence of the underlying dermis. This has been demonstrated by exogastrulation as well as in vitro experi- 
ments, and with both methods ectoderm alone forms a disorganized mass of epithelial cells, while ectoderm underlain by dermis develops into definitive epidermis (Holtfreter, '31 b, '33 d). In the blastema, however, in many cases typical epidermis occur's which is underlain directly by host mesenchyme, with no trace of dermis present. In all these instances blastema mesenchyme evidently has the same influence on the differentiation of gastrula ectoderm as the dermis in normal development. Whether or not this relation should be called an induction is a matter of definition, but it is clearly a definite morphogenic influence of the regenerating mesenchyme on the embryonic tissue. Since the normal effect of the dermis on epidermis formation is well established, this conclusion seems certain.

The epidermal vesicles in the blastema have the outside of the epidermis facing the inside of the vesicle. This has been described above and is evident in several of the figures. The polarity is shown in grafts fixed after 7 to 11 days by the position of cilia, distribution of pigment, and orientation of the suckers, although all these criteria are not present in each case. In the older grafts the orientation of the epidermis is obvious from the position of the superficial and sensory layers. There is no exception to this result, and there are only two cases in which the polarity of the epithelium could not be determined.

The way in which this unexpected result is brought about is illustrated in figures 8 to 11. During the first day after operation most of the grafts round up to some extent with the outer ectodermal surface outside, just as ectodermal explants round up in vitro. During the second day the edges of the transplants usually begin to curl up in the opposite direction. By the end of the third day the curling edges of most of the grafts have come together, so that an inside out vesicle is formed. At this time there is either a single small lumen or several small lumina situated toward the original outer surface of the graft. Later the lumen of the transplant enlarges by growth of the superficial epithelial layer, and subsequently by 
disintegration of some of the cells in the center of the graft. Even the vesicles formed from grafts allowed to round up into a ball before transplantation have the outside of the epidermis facing the inside of the vesicle. And the intermediate stages show that the early development of the ectodermal balls is essentially similar to that of the flat ectodermal grafts just described.

The causal factors involved in this method of development are only partly evident. The initial rounding up of the graft is similar to the rolling up of ectoderm in vitro, and presumably the same factors are at work. The secondary curling of the edges of the graft in the opposite direction is due to growth rather than simple cellular movement, which is shown by the presence of mitotic figures, and by the length of time required for the process to occur. But what controls the direction of growth is still obscure. There are some sucker cells in most of the grafts, and the normal early sucker is a cupshaped organ. This suggests that the beginning of the secondary curling of the grafts may be due to an early stage in sucker morphogenesis. However, the series of intermediate stages in figures 8 to 11 when compared to early sucker development do not make this explanation convincing. It is hoped that further work will give more information on this point.

\section{CONCLUSIONS}

1. Gastrula ectoderm in blastema tissue develops into epidermis with superficial and sensory layers, nervous tissue, suckers, cartilage, and possibly dermis. Blastema mesenchyme is therefore a very favorable environment for the development of gastrula ectoderm, and it differs in its effect on ectodermal grafts from any of the media previously studied.

2. The definitive epidermis is usually underlain directly by host tissue with no trace of dermis present. Blastema mesenchyme, therefore, has the same formative influence on gastrula ectoderm as the dermis in normal development.

3 . The epidermis forms an oval vesicle with the outside of the epidermis invariably facing inward. This condition is 
brought about by a growth process which is opposite in direction to the way in which explants normally curl up in vitro. Grafts allowed to roll up in salt solution before transplantation act in the same way.

4. The various tissues formed from ectoderm in the blastema are not confined to their presumptive gastrula regions. Both epidermis and nervous tissue come about as often from either presumptive epidermis or neural plate. And typical suckers come with equal frequency from any ectodermal area.

\section{LITERATURE CITED}

BavtzmanN, H. 1929 Über bedeutungsfremde Selbstdifferenzierung aus Teilstücken des Amphibienkeimes. Naturwiss., Bd. 17, S. 818-827.

Emerson, H. S. 1940 Embryonic induction in regenerating tissue of Rana pipiens and Rana elamitans larvae. J. Exp. Zool., vol. 83, pp. 191-221.

Harrison, R. G. 1938 Die Neuralleiste. Verh. d. Anat. Ges., Bd. 85, s. 3-30. HOLTFRETER, J. $1929 \mathrm{~b}$ Über histologische Differenzierungen von isoliertem Material jüngster Amphibienkeime. Verh. d. D. Zool. Ges., Bd. 33, S. 174-181.

1931 a Potenzprüfungen am Amphibienkeim mit Hilfe der Isolationsmethode. Verh. d. D. Zool. Ges., Bd. 34, S. 158-166.

$1931 \mathrm{~b}$ Über die Aufzucht isolierter Teile des Amphibienkeimes. II. Züchtung von keimen und Keimteilen in Salzlösung. Arch. f. Entwmech. d. Organ., Bd. 124, S. 404-466.

1933d Die totale Exogastrulation, eine Selbstablösung des Ektoderms vom Entomesoderm. Arch. f. Entwmech. d. Organ., Bd. 129, S. $669-793$.

1938 a Differenzierungspotenzen isolierter Teile der Urodelengastrula. Arch. f. Entwmech. d. Organ., Bd. 138, S. 522-656.

1938 b Differenzierungspotenzen isolierter Teile der Anurengastrula. Arch. f. Entwmech. d. Organ., Bd, 138, S. 657-738.

KUSCHE, W. 1929 Interplantation umsehriebener Zellbezirke aus der blastula und der Gastrula von Amphibien. I. Versuche an Urodelen. Arch. $f$. Entwmech. d. Organ., Bd. 120, s. 192-271.

1930 Interplantation umschiebener Zellbezirke aus der Blastula der Gastrula von Amphibien. Naturwiss., Bd. 18, S. 913-914.

VoGT, W. $1929 \mathrm{~b}$ Gestaltungsanalyse am Amphibienkeim mit örtlicher Vitalfärbung. II. Teil. Gastrulation und Mesodermbildung bei Urodelen und Anuren. Arch. f. Entwmech. d. Organ., Bd. 120, S. 384-706. 


\section{PLATES}




\section{PLATE 1}

\section{FXPLANATION OF FIGURES}

2 The gastrula ectoderm has formed an oval epithelial vesicle surrounded by blastema mesenchyme. Fixed after 10 days. $\times 100$.

3 Portion of a vesicle similar to that shown in figure 2. A dermis of fibroblasts and parallel collagenous fibers is present between the epithelium and the blastema mesenchyme. Fixed after 10 days. $\times 200$.

4 Presumptive epidermis has formed both an epithelial vesicle and a mass of nervous tissue which is separated into fibrous and cellular portions. Fixed after 10 days. $\times 100$.

5 Gastrula ectoderm far removed from the presumptive sucker region has transformed entirely into typical tall, hyaline sucker cells which are in active secretion. Fixed after 10 days. $\times 75$.

6 A small sucker of normal cup-shaped form makes up part of the wall of an epithelial vesicle. Fixed after 7 days. $\times 75$. 
HEVRY S. HMERSOY

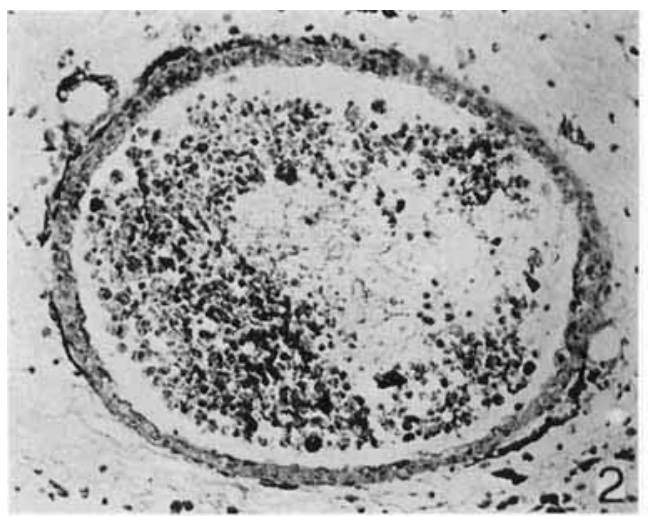

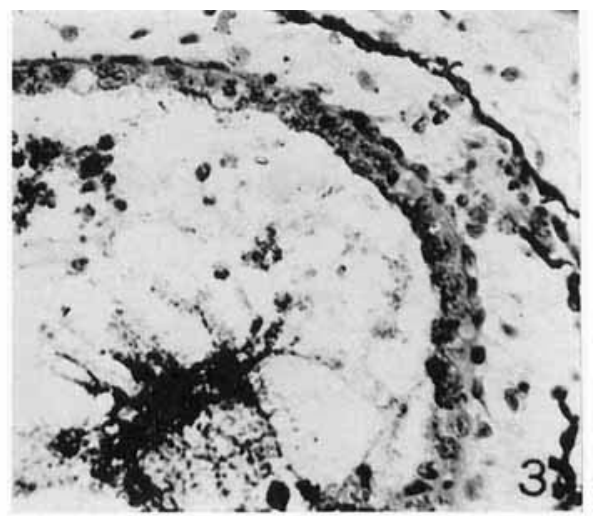
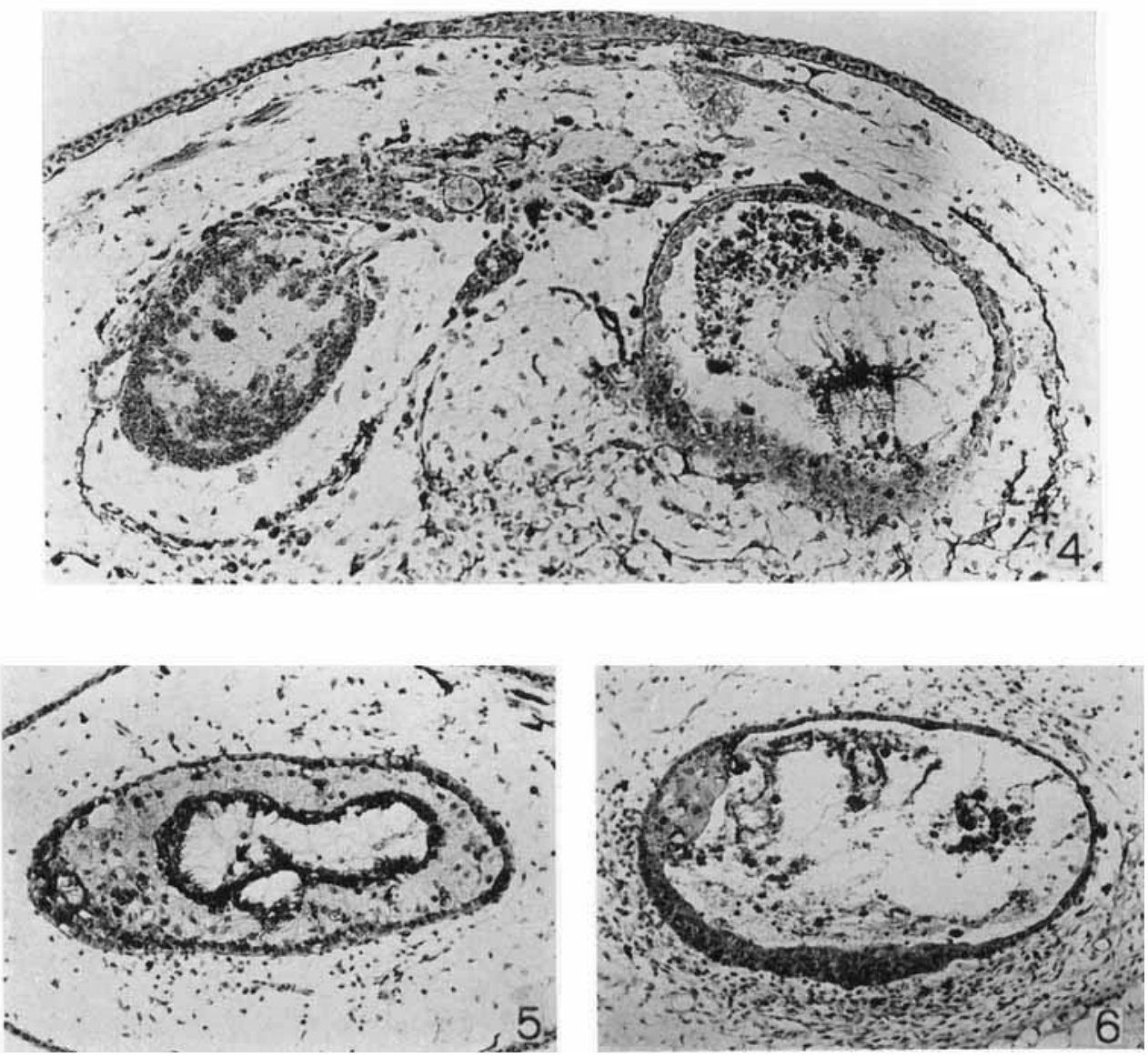
PLATE 2

EXPLANATION OF FIGURES

7 The gastrula ectoderm has developed into definitive epidermis with typical superficial and sensory layers, underlain directly by blastema mesenclyyme. Fixed after 20 days. $\times 200$.

8 The transplant is largely rounded $\mathrm{up}$ with the outer ectodermal surface outside. Fixed after 1 day. $\times 75$.

9 The graft is similar to figure 8 except that the ediges are beginning to curl up in the direction opposite to the original curvature. Fixed after 2 days. $\times 75$.

10 The secondary curling of the edges of the graft has progressed further than in figure 9 . Fixed after 2 days. $\times 75$.

11 The original inner side of the ectoderm covers the entire outer surface of the graft. There are several small lumina surrounded by early sucker cells. Fixed after 3 dinys. $\times 75$. 

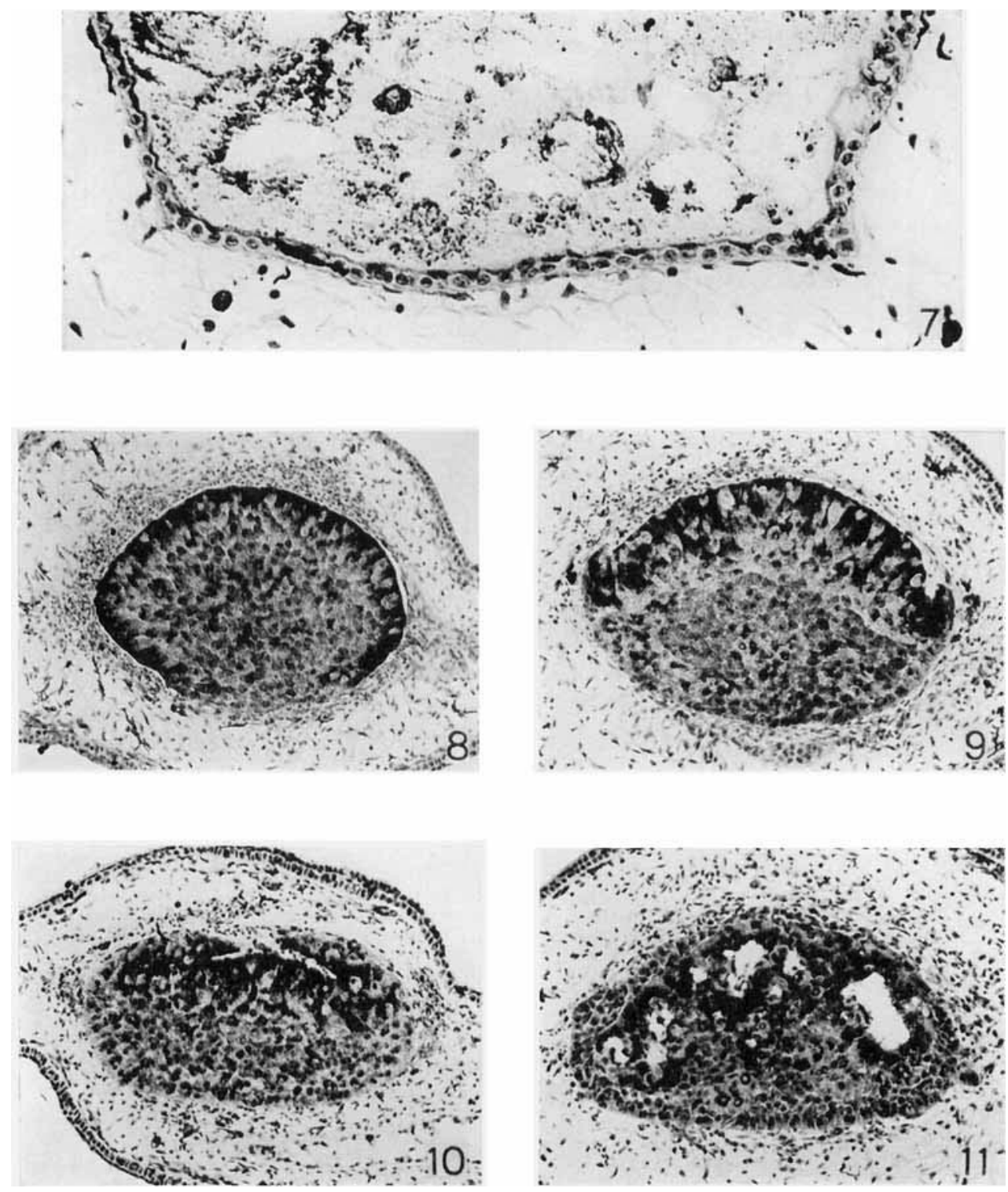